\title{
Coaxing HESC to form Oocyte-Like Structures by Co-Culture with Testicular Extract and Hormones
}

\author{
Jinlian Hua ${ }^{*}, 1,2$ and Kuldip S. Sidhu ${ }^{2,3}$ \\ ${ }^{I}$ College of Veterinary Medicine, Shaanxi Center of Stem Cell Engineering and Technology, Northwest A\&F University, \\ Yangling, Shaanxi 712100, China \\ ${ }^{2}$ Stem Cell Group, Diabetes Transplant Unit, Prince of Wales Hospital, Sydney, 2031 Australia \\ ${ }^{3}$ Stem Cell Lab, Faculty of Medicine, School of Psychiatry, University of New South Wales, Sydney, 2052 Australia
}

\begin{abstract}
Reports have shown that murine embryonic stem cells (mESC) can differentiate into primordial germ cells (PGC) and then to early gametes (oocytes and sperm) that after fertilization form blastocysts. Preliminary studies indicated that hESC also have the potential to differentiate into germ cells. Currently, there are no reports on directed differentiation of hESCs into oocytes. Here, we investigated the effects of human fetal testicular extracts (HFTE) and hormones i.e. follicle-stimulating hormone (FSH), human chorionic gonadotropin (hCG) to coax hESC to differentiate into oocytes. The embryoid bodies (EBs) derived from hESC formed ovarian-like structures (OLS) after treatment with HFTE for 7 days and with hormones (FSH + hCG) for 20-30 days. OLS exhibited typical oocyte-like spherical shape of variable sizes and some with zona pellucida-like covering RT-PCR, immunological fluorescence staining and flow cytometry analyses showed that these structures are positive for specific germ cell and oocyte markers such as OCT4, SCP3, C-KIT and DDX4, STELLA, FIGLA, GDF9, NANOG, FSHR, ZP1, ZP2 and ZP3. Quantitative RT-PCR analysis showed that FSHR, GDF9 and FIGLA were up-regulated during OLS differentiation from EB in a time-dependent manner. These results demonstrated that hESC have the ability to differentiate into ovarian structures. This study thus provides an in vitro model to study germ-cell formation from hESC and these germ cells may generate a potential source of oocytes for therapeutic cloning.
\end{abstract}

Keywords: Germ cells, primordial germ cells (PGC), embryonic stem cells (ESC), oocyte, follicle stimulating hormone (FSH), human chorion gonadotropin (hCG).

\section{INTRODUCTION}

Germline transmission is one of the most important subjects in genetics, embryology, including development biology. Germ cells are highly specialized cell populations that are indispensable for the continuation and evolution of the species. Human germ cell development has been difficult to study because the important early events occur after implantation in womb [1]. Human embryonic stem cells (hESC) are derived from the inner cell mass of the human blastocyst, with the ability to differentiate into almost all cell types in the human body, and thus potentially provide unlimited sources for organ and cell replacement therapies [2].

Recently, reports have shown that murine embryonic stem cells (mESC) can differentiate into primordial germ cells (PGC) and subsequently develop into early gametes (oocytes and sperms) that after fertilization form blastocysts [3-6]. Preliminary studies indicated that hESC most likely also have the potential to differentiate into germ cells [7-11]. Currently, there are no reports on directed differentiation of hESC into oocytes. Derivation of oocytes from stem cells

*Address correspondence to this author at the College of Veterinary Medicine, Shaanxi Center of Stem Cell Engineering and Technology, Northwest A\&F University, Yangling, Shaanxi 712100, China; Tel: 86-2987080068; Fax: 86-29-87080068; E-mail: jlhua2003@126.com will be a potential resource for therapeutic cloning. Thus, we may circumvent the ethical issues pertaining to the use of discarded embryos. In this study, we investigated the effects of human fetal testicular extracts (HFTE) in combination with FSH, hCG and fetal bovine serum (FBS) to coax differentiation of hESC to oocytes. This study provides evidence that OLS can be produced from hESC and that the same may provides an in vitro model to study germ cell formation and also as a potential source of oocytes for therapeutic cloning.

\section{MATERIALS AND METHODS}

All reagents including culture media and sera were obtained from Gibco/Invitrogen (Carlsbad, CA, USA), Sigma (St. Louis, MO, USA) and Hyclone (Logan, Utah USA). This study to work on hESC, human fetal testis and mouse testes had Institutional ethics approval (HREC 02247).

\section{Embryonic Stem Cells}

The hESC line, Endeavor-1 established in-house [12] was used for this study. The hESC colonies were maintained in gelatin-coated six-well culture plates (Becton Dickinson, NJ, USA) on gamma-irradiated (45Gy) primary human fetal fibroblast (HFF, passage 6) feeder layers $\left(3.0 \times 10^{5}\right.$ cells/ 
well) and cultured at $37^{\circ} \mathrm{C}, 5 \% \mathrm{CO}_{2}$ in serum replacement (SR) medium consisting of Dulbecco knockout (KODMEM) high glucose, supplemented with $20 \%$ knockout serum replacer (Gibco, Carlsbad, CA), $2 \mathrm{mM}$ L-glutamine, $0.1 \mathrm{mM}$ nonessential amino acids, $0.1 \mathrm{mM} 2$-mercaptoethanol, 1\% insulin-transferrin-selenium (ITS), basic fibroblast growth factor (bFGF, $4 \mathrm{ng} / \mathrm{ml}$ ), $25 \mathrm{U} / \mathrm{ml}$ penicillin, and $25 \mu \mathrm{g} / \mathrm{ml}$ streptomycin. This study to work on hESC and HFF lines had Institutional ethics approval (HREC 01270). The subculturing of hESC colonies was performed every 5-7 days by using $0.05 \%$ trypsin for $2 \mathrm{~min}$ [12].

\section{Formation of Embryoid Bodies (EBs)}

Undifferentiated hESC colonies were dissected out by using collagenase type IV $(1 \mathrm{mg} / \mathrm{ml})$ for $7-15 \mathrm{~min}$ at $37{ }^{\circ} \mathrm{C}$ after gently washing twice with phosphate-buffered saline (PBS) without $\mathrm{Ca}^{2+}$ and $\mathrm{Mg}^{2+}$. These colonies of $\mathrm{hESC}$ were allowed to settle at the bottom of $15 \mathrm{ml}$ tube for 15-20 min and cultured in SR medium in non-tissue culture plates in suspension culture without bFGF for 4 days to produce EBs, and the viability of EBs was higher than $95 \%$ based on 6 carboxyfluorescein diacetate (CFDA) and propidium iodide (PI) [12].

\section{Preparation of Testicular Extracts}

Fresh human fetal testes (older than 4 months) after therapeutic termination of pregnancies were collected and cut into smaller pieces $2 \times 2 \mathrm{~mm}^{3}$ pieces and incubated with $0.1 \%$ collagenase at $37^{\circ} \mathrm{C}$ for $25 \mathrm{~min}$, followed by in $10 \mu \mathrm{g} / \mathrm{ml}$ DNase for $5 \mathrm{~min}$, then $0.25 \%$ trypsin for $5-10 \mathrm{~min}$, neutralized with DMEM containing $10 \%$ FBS. The pellets were collected after spinning at $1300 \mathrm{rpm}$ for $5 \mathrm{~min}$ and washed in ice-cold PBS, and resuspended in one volume of lysis buffer (10 mM HEPES, $\mathrm{pH} 8.2,50 \mathrm{mM} \mathrm{NaCl}, 5 \mathrm{mM} \mathrm{MgCl}_{2}, 1$ $\mathrm{mM}$ dithioreitol, $25 \mu \mathrm{g} / \mathrm{ml}$ protease inhibitors and $0.1 \mathrm{mM}$ henylmethylsulfonyl fluoride). The pellets were snap-frozen in liquid nitrogen for 2 minutes, thawed, and disrupted by vortexing. After centrifugation $\left(15,000 \mathrm{~g}\right.$ for $15 \mathrm{~min}$ at $\left.4^{\circ} \mathrm{C}\right)$, the supernatant (extract) was used fresh or frozen in liquid nitrogen and stored at $-80^{\circ} \mathrm{C}$ [13]. Protein concentration of the extract was estimated spectrophotometerically.

\section{Differentiation Protocol (Supplementary Fig. 1)}

Day 4 EBs were selected and seeded onto $5 \mu \mathrm{g} \mathrm{ml}^{-1}$ laminin-coated inserts for incubation in 24 or 6 well culture plates. According to the flow diagram three different treatment regiments were selected during the induction phase: (1) Control medium (SR-FBS), KO-DMEM supplemented with $20 \%$ fetal bovine serum (FBS, Hyclone), $2 \mathrm{mM}$ L-glutamine, $0.1 \mathrm{mM}$ nonessential amino acids, $0.1 \mathrm{mM} \mathrm{2-}$ mercaptoethanol, $1 \%$ ITS, $25 \mathrm{U} / \mathrm{ml}$ penicillin, and $25 \mu \mathrm{g} / \mathrm{ml}$ streptomycin; (2) Hormone medium consisting of 0.1 international units (IU) FSH (Sioux Biochem, Sioux City, IA), 1 IU hCG (Sioux Biochem), and $1 \mu \mathrm{g} / \mathrm{ml}$ estrodial (Sigma) in TCM199 (Sigma), supplemented with 10\% FBS (Hyclone), $5 \mu \mathrm{ml}^{-1}$ ITS (Gibco), $0.23 \mathrm{mM}$ pyruvic acid (Gibco), $1 \mathrm{ng} \mathrm{ml}^{-1}$ EGF (Sigma), and (3) Testicular extracts medium consisting of $50 \mu \mathrm{g} / \mathrm{ml}$ testicular extracts in medium (1). EBs were maintained in these culture media by replacing half the medium with fresh medium every 3 days. The large cells (within 7-10 days) extruded from the aggregates and were then collected physically by pipetting from the culture and replated in fresh growth medium in 24-well plates. On day 11, all media were changed into maturation medium, that consisted of TCM199 (Sigma), supplemented with 10\% FBS (Hyclone), $5 \mu \mathrm{ml}^{-1}$ ITS (Gibco), $0.23 \mathrm{mM}$ pyruvic acid (Gibco), $1 \mathrm{ng} \mathrm{ml}^{-1}$ EGF (Sigma), $0.1 \mathrm{IU} \mathrm{ml}^{-1} \mathrm{FSH}$ (Sioux Biochem, Sioux City, IA), and $1 \mathrm{IU} \mathrm{ml}^{-1} \mathrm{hCG}$ (Sioux Biochem). Cultures were monitored for morphological changes each day and samples also collected for RNA extraction and immunolocalisation at Day 10, 20 and 34.

\section{Flow Cytometry}

Briefly, germ cells derived from ESC were sorted based on DDX4 expression. Cells were dissociated with $0.1 \%$ collagenase IV, TrypleTM Select and neutralized with DMEM with $10 \%$ FBS, washed twice with PBS and then resuspended in PBS containing $0.5 \%$ BSA. Aliquots of $1 \times 10^{6}$ cells were incubated in $200 \mu 1$ of PBS/BSA containing of primary antibody DDX4 $\left(1 \mu \mathrm{g} \mathrm{ml} l^{-1}\right)$ monoclonal antibody (Abcam, MA, USA) on ice for 30 minutes. An isotype control was used to exclude non-specific binding (negative control, no primary antibody). After washing with PBS/BSA, fluorescent secondary antibodies (donkey anti-rabbit 488, 1:500) were added for $30 \mathrm{~min}$ on ice. This was following by rinsing the samples twice with PBS/BSA and filtered through a $40 \mu \mathrm{m}$ pore-size nylon screen (Falcon, BD). Approximately $1 \times 10^{6}$ cells $/ \mathrm{ml}$ in PBS/BSA were used for sorting. The flow cytometry was performed on a FACStar Plus (Becton Dickinson) equipped with dual 488-nm argon.

\section{Marker Analyses by RT-PCR}

At day 11, 20 and 34, random hESC samples under three different conditions (Flow diagram) were collected for RNA extraction as described below and analyzed for gene expression specific to germ cell markers i.e. VASA, STELLA, DAZL, C-KIT; meiosis markers SCP3, STRA; male marker: SRY, and the oocyte-specific markers FIGLA, GDF9, FSHR, ZP1, ZP2 and ZP3. The expression of these markers was compared with that of 19-20 week-old human fetal ovaries, testes, human fetal fibroblasts (HFF10) and human fetal ovary germ cells (hOGC). The culture of human fetal ovary germ cells was based on testicular cell culture [6].

Total RNA was isolated with the RNeasy Mini kit (Qiagen, Hilden, Germany) or Trizol (Invitrogen, Carlsbad, CA, USA) with DNase treatment. The first strand of cDNA was synthesized using $200 \mathrm{ng}$ of total RNA with MMLV-RT (Invitrogen) and an oligo (dT) primer (Invitrogen), using the Superscript III One-Step RT-PCR system (Invitrogen). The reverse transcription-polymerase chain reaction (RT-PCR) was analyzed in $2 \%$ agarose (Invitrogen), stained with ethidium bromide or SYGR (Invitrogen, Carlsbad, CA, USA) and visualized under UV illumination. The PCR conditions and the primers are shown on Table $\mathbf{1}$.

\section{Quantitative PCR}

Quantitative PCR analyses of the expressions of oocyte and germ cell specific markers in undifferentiated hESCs, EBs(D4), OLS(D11, D28), human fetal testis and ovary. The cDNA was produced using Thermo Absolute Blue QPCR SYBR\#\#\# Green Mix (Abgene, Epsom, UK). The 
Table 1. The Primers and PCR Conditions

\begin{tabular}{|c|c|c|c|c|c|}
\hline Gene Name & Sense & Anti Sense & Product Size (bp) & $\begin{array}{c}\text { Annealing } \\
\text { Temperature }\left({ }^{\circ} \mathrm{C}\right)\end{array}$ & Source \\
\hline C-KIT & 5'-tgacttacgacaggctcgtg-3' & 5'-aaggagtgaacagggtgt gg-3' & 155 & 57 & XM942460 \\
\hline SRY & $5^{\prime}$-cctctccttcttgtgecttg- $3^{\prime}$ & 5'-gggagacagcaactc tcagg-3' & 236 & 57 & ВС004299 \\
\hline STRA & $5^{\prime}$-aatccccatgacagagcaac-3' & $5^{\prime}$-aacctgccactttgaggc ta-3' & 227 & 62 & NM182489 \\
\hline STELLA & 5'-ctcaaatctcctccgagacg-3' & 5'-gtacgaactccgcccagtaa-3' & 238 & 60 & $\mathrm{BC} 125145$ \\
\hline VASA & $5^{\prime}$-aagagaggctatcgagatgga $3^{\prime}$ & $5^{\prime}$-cgttcacttccactgecacttctg-3' & 238 & 57 & Zeeman et al., 2002 [12] \\
\hline ZP1 & $5^{\prime}$-cgccatgttctctgtctcaa-3' & $5^{\prime}$-cgtttgttcacatcccagtg-3' & 162 & 60 & NM207341 \\
\hline $\mathrm{ZP} 2$ & 5' -cagaccaccttccatccagt-3' & 5'-acctcctcccctgtttcact-3' & 217 & 58 & NM003460 \\
\hline FSHR & 5"tgagggccaggtcgactt ac-3' & 5'-tgaggctggcttccatgag-3' & 342 & 62 & Qing et al., 2004 [14] \\
\hline OCT4 & 5'-attcagccaaacgaccat ct-3' & 5'-cagcagcctcaaaatcctct-3' & 371 & 59 & NM002701 \\
\hline NANOG & 5'-cctatgcctgtgatttgtgg-3' & 5'-ctgggaccttgtcttccttt-3' & 208 & 59 & NM024865 \\
\hline$\beta$-ACTIN & 5'-acggcatcgtcaccaact-3' & 5'aggaaggaaggctggaag ag3' & 541 & 59 & NM001101 \\
\hline
\end{tabular}

PCR amplifications were performed with the Stratagene Mx3005P Real-Time PCR System (Stratagene, Santa Clara, USA) at $95^{\circ} \mathrm{C}$ for $15 \mathrm{~min}$ to activate the polymerase, followed by 40 cycles of $95^{\circ} \mathrm{C}, 15 \mathrm{sec}$; and an annealing/ extension step $\left(1 \mathrm{~min}\right.$ at $\left.60^{\circ} \mathrm{C}\right)$. The SYBR green signal was read at the end of every annealing/extension step. Finally, a melting curve was run to analyze the quality of the PCR reaction. The results were analyzed using MxPro3005P software (Stratagene, Santa Clara, USA) and Microsoft Excel (Microsoft Corporation, Redmond, WA, USA). All experiments included negative controls consisting of no cDNA for each primer pair. Primers were designed to span exons to distinguish cDNA from genomic DNA products. The primers for Quantitative RT-PCR are shown in Table 2.

\section{Immunofluorescent Staining}

At day 11, 20 and 34 sample of three different cultures were randomly examined for the expression of OCT4, C-
KIT, NANOG, the mouse homologue Mvh (DDX4 or VASA), SCP3, ZP3, and FSHR. Ovarian germ cells derived from 19 week human fetal and undifferentiated hESC cultures were also analyzed as controls by immunofluorescence for the expression of the germ cell markers OCT4, DDX4, and C-KIT, NANOG, SCP3, ZP3, and FSHR. The cultures were fixed using 4\% paraformaldehyde (PFA) for 15 minutes followed by three washes in cold PBS for 5 minutes. Washed cultures were treated with blocking solution (PBST $+1 \% \mathrm{BSA}$ ) for a minimum of $30 \mathrm{~min}$ before being washed with PBS and stained with primary antibodies for OCT4 (1:500, Santa Cruz Biotechnology Inc., CA, USA), C-KIT (1:300, Santa Cruz Biotechnology Inc.), DDX4(1:1000, Abcam), SCP3 (1:300, Abcam), ZP3 (1:100, SantaCruz Biotechnology Inc.), and FSHR (1:200, AbD Serotec, Kidlington, UK) overnight at $4{ }^{\circ} \mathrm{C}$. Antibodies were diluted according to manufacturer or provider's instructions. Cultures were washed with PBS and incubated in the appro-

Table 2.The Primers for Quantitative RT- PCR

\begin{tabular}{|c|c|c|c|}
\hline OCT4 & $5^{\prime}$ tgggctcgagaaggatgtg $3^{\prime}$ & $5^{\prime}$ gcatagtcgctgcttgatcg $3^{\prime}$ & 58 \\
\hline FSHR & $5^{\prime}$ tttcgtggggetgagetttg- $3^{\prime}$ & 5'-aaaggcacagcaatggctgg-3' & 78 \\
\hline GDF9 & $5^{\prime}-$ tag tcc acc cac aca cct ga-3' & 5 '-cca gaa gcc tga gaa cca ag-3' & 197 \\
\hline $18 \mathrm{~S}$ & 5'gttccgaccataaacgatgc $3^{\prime}$ & 5'aaccagacaaatcgctccac3' & 298 \\
\hline
\end{tabular}


priate Alexa Fluor\#\#\# Donkey anti-mouse, rabbit or goat conjugates, respectively (Invitrogen). The fluorescent secondary antibodies were added and incubated for 30 minutes at room temperature in the dark. Cells were washed with cold D-PBS three times for 5 minutes. Cultures were mounted with prolonged fluorescent 4, 6-diamidino-2-phenylindole (DAPI) (Invitrogen). Stained cells were visualized under a Zeiss Axiosko2 fluorescent microscope (Zeiss AxioVision, Göttingen, Germany) using the appropriate excitation wavelength filters.

All the presented experiments were replicated at least 3 times and the data were analysed by Microsoft Excel.

\section{RESULTS}

\section{hESC Morphology and EB Formation}

In this experiment, the karyotype of Endeavour-1 (P1152) was female, i.e. $46 \mathrm{XX}$ and was used to differentiation into oocytes. hESC grew with distinct stem cell morphology with discrete outer boundaries and maintained undifferentiated state under the culture conditions described. hESC colonies in suspension cultures formed embryoid bodies (EBs), nearly 100-200 $\mu \mathrm{m}$.

\section{Differentiation of hESC into Ovarian Follicle-Like Structures Derived from EBs}

The day 4 EBs attached to the plastic plates and the peripheral cells of the EBs formed monolayers that continued to spread some small clusters around the center of the EB. By day 10, most EBs attached to the plastic surface and some large PGC-like cells were observed to spread out. A few large cell colonies that resembled early germ cell clusters formed at day 20 after the initiation of differentiation (Fig. 1, upper panel, arrows). The cells in the centre of clusters degenerated and the peripheral cells had varied morphological shapes with some remained floating. A few ovarian-
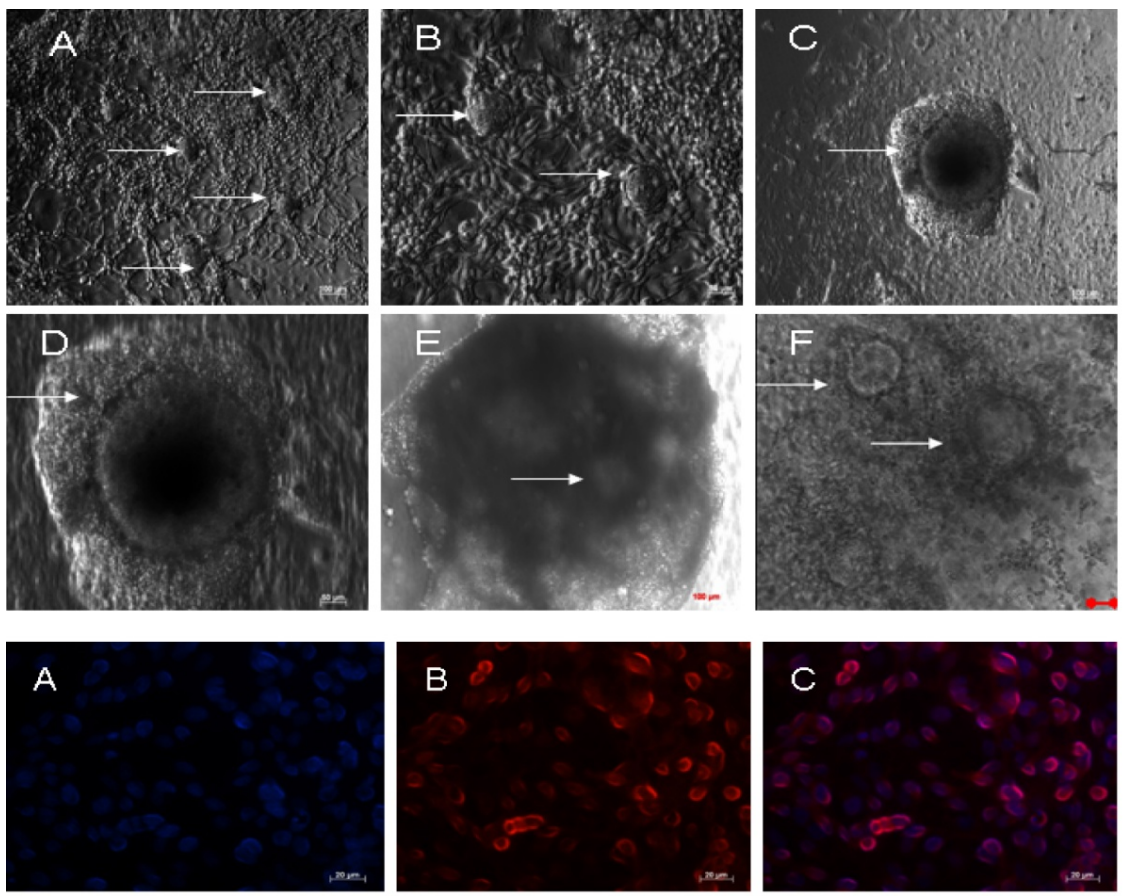

DDX4
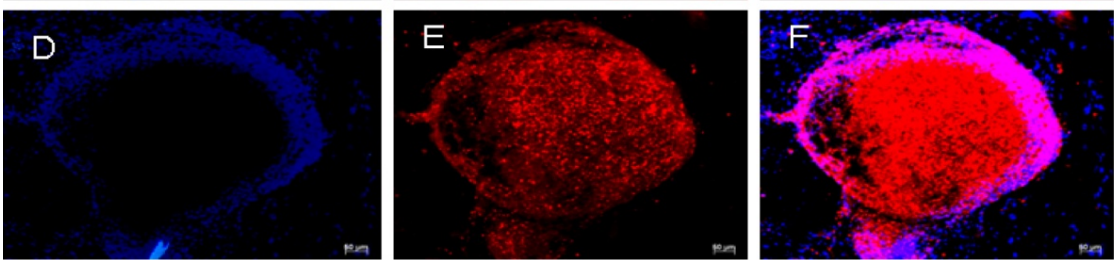

C-KIT
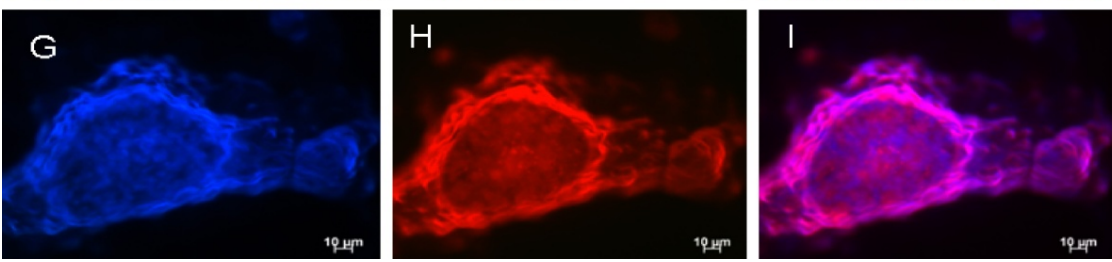

SCP3

Fig. (1). Upper panel: hESC forming ovarian follicle-like structures in vitro after treatment with testicular extracts in combination with hormones. A-F, Typical ovarian follicle-like structures are indicated by arrows. Granulosa-like cells are surrounding the follicles derived from hESC (C and D arrows). Scale bar, A, C, E=100 $\mu \mathrm{m} ; \mathbf{B}, \mathrm{D}=50 \mu \mathrm{m} ; \mathrm{E}=20 \mu \mathrm{m}$. Lower panel: Ovarian follicle-like structures are positive for C-DDX4 $($ Scale bar $=20 \mu \mathrm{m}), \mathrm{C}-\mathrm{KIT}($ Scale bar $=50 \mu \mathrm{m})$ and SCP3 $($ Scale bar $=20 \mu \mathrm{m})$. 
like structures and large germ cell aggaregates appeared in 3 different types of media $+/$ - extracts/hormone treatment (Fig. 1) between 20-30 days after treatment. Several days later, these cells differentiated further into follicle-like structures (Fig. 1) with a resemblance to primordial and primary follicles normally observed only at the dictyate stage of meiosis in ovaries [15]. The appearance of the follicle-like structures strongly suggests that ovarian germ cell-supporting cells, such as granulosa cells, are formed during in vitro differentiation of hESC.

A significant $(\mathrm{P}<0.05)$ difference was observed between different treatments (Fig. 3). Cultures with HFTE treatment resulted in higher proliferation rate of germ cells that formed ovarian-looking structures compared to SR-FBS and hormone treated cells (Fig. 2). Follicle-like structures started forming between day 20-30 that resulted in the appearance of ovarian-like structures (Figs. 1,2). The structures varied in size with the larger ones being 70-200 $\mu \mathrm{m}$ in diameter.
These structures seemed to contain primary follicles like cells, which is similar as a developmental stage of oocytes based on size and structures in which some cells displayed a zona-like structure membrane with a few cell layers surrounding them [14]. Similar morphological changes were evident in some day 10-20 EBs that were treated with hormones and SR-FBS. However, more oocyte-like structures were observed in the HFTE group than in the hormone or SR-FBS treated groups (Fig. 3). Some putative oocytelike cells were formed and developed into blastocyst-like structures between 28-40 days (Fig. 2). However, they did not continue to form unified confluent cultures and clumps spread all over the dish which were mixed with other types of cells such as neural rosettes and vascular endothelial-like cells. An obvious beating rhythm indicative of their differentiation into cardiac muscle cells, endothelial, vascular and neural-like cells were also observed on days 20-50 with few cells actually developing into mature oocytes.
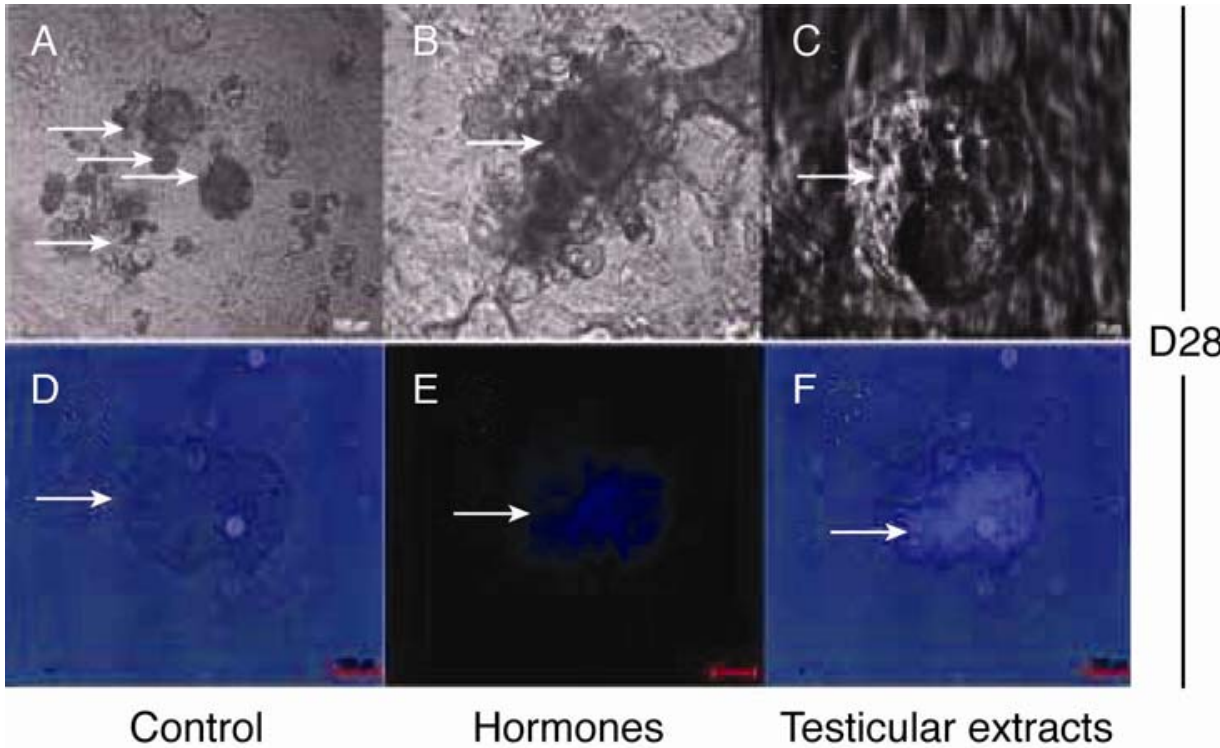

Fig. (2). Ovarian oocyte-like structures and blastocyst like structures derived from hESC. A-B, Ovarian oocyte-like cells (arrows) at day 28 after treatment. A, Scale bar $=100 \mu \mathrm{m} ; \mathbf{B}$, Scale bar $=50 \mu \mathrm{m}$. C-F, Oocyte-like cells further developed into blastocyst-like structures. $\mathbf{C}$ at day 31, Scale bar $=20 \mu \mathrm{m} ; \mathrm{D}-\mathrm{F}$ at day 38, Scale bar $=100 \mu \mathrm{m}$. D, DIC image; E, Hoechst33342 staining; F, Merge of D and E.

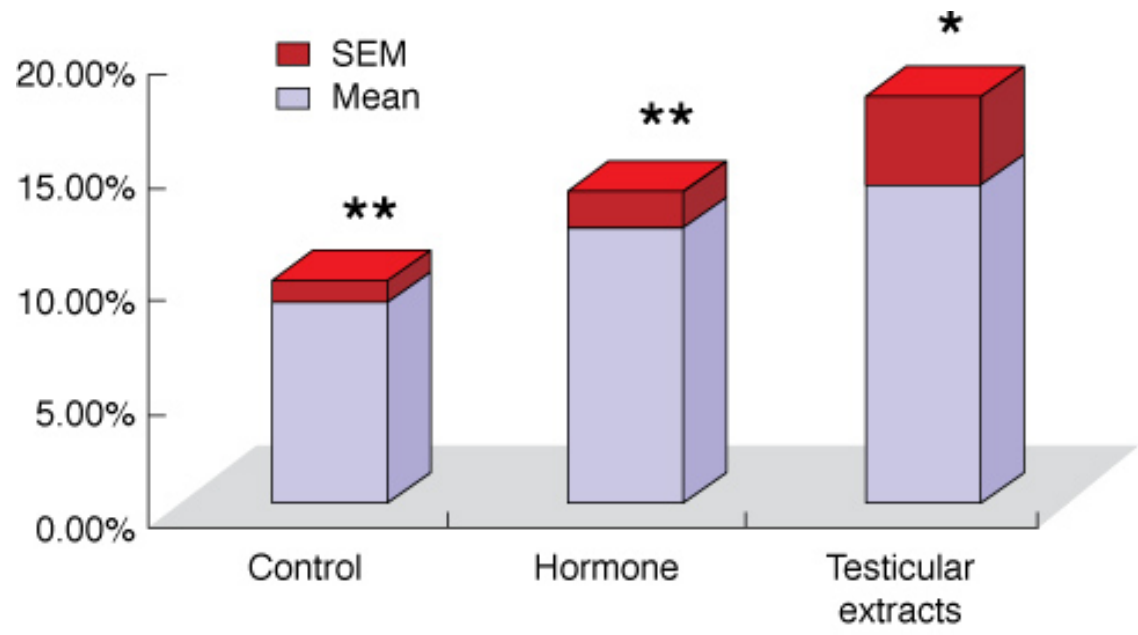

Fig. (3). Formation of ovarian-like structures (OLS), EBs cultured in testicular extracts formed significantly higher OLS in comparison to hormone treated and control groups $(\mathrm{P}<0.05, \mathrm{n}=3)$. Data presented as mean \pm SEM per EB in different groups. 
Characterization of Ovarian-Like Structures Derived from hESC

Immunofluorescence staining of typical ovarian-like structures (OLS) and day 11,20, and 34 of cultures identified cells that were positive for OCT4, DDX4, C-KIT, SCP3 and ZP3 (Fig. 1 and Figs. 4-6). Flow cytometry ana- lysis showed that $12.54 \%$ cells were positive for DDX4 at day 20 after HFTE (Fig. 5).

RT-PCR analysis of day 11,20 , and 34 treated cultures confirmed positive expressions of the germ cell markers i.e. OCT4, DDX4, STELLA, DAZL and C-KIT, SCP3, and oocyte markers: FSHR, GDF9, FIGLA, ZP1, ZP2 and ZP3,
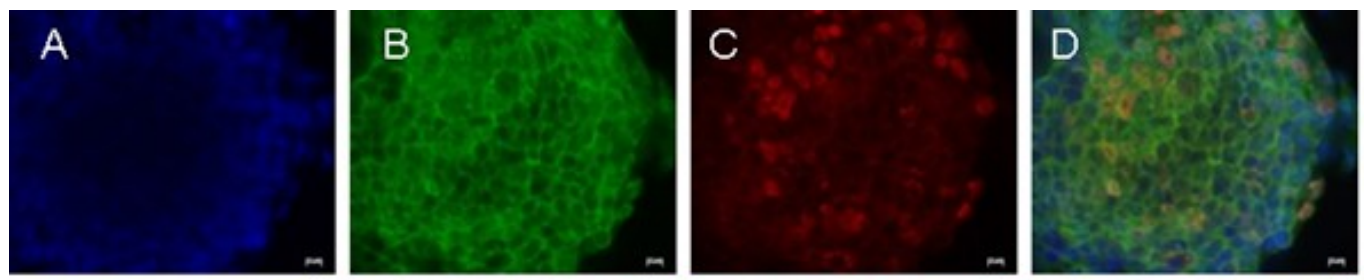

\section{Control}
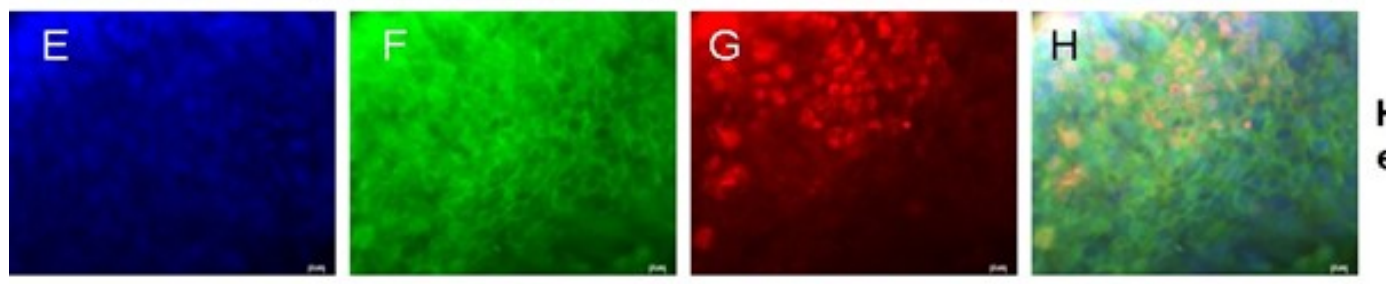

\section{Hormon}

e
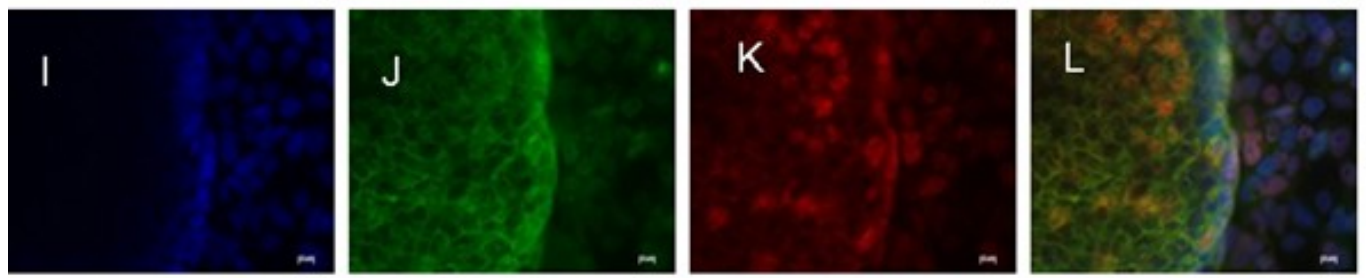

DAPI

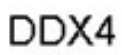

OCT4

\section{MERGE}
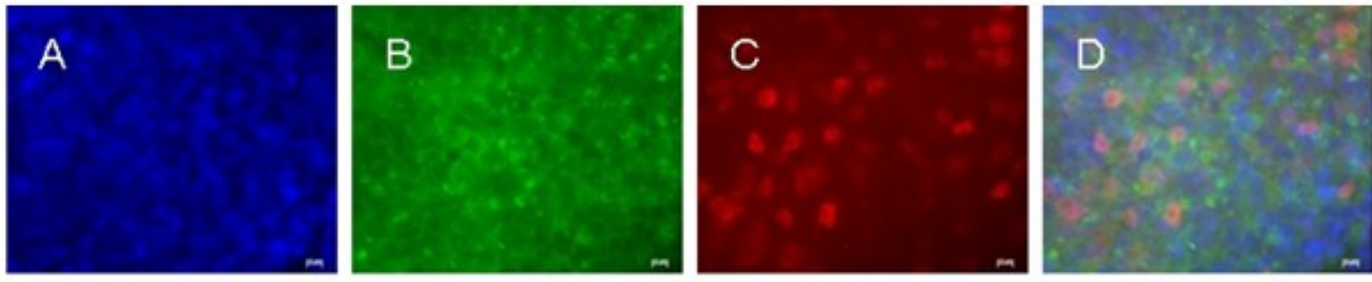

Testicular

extracts
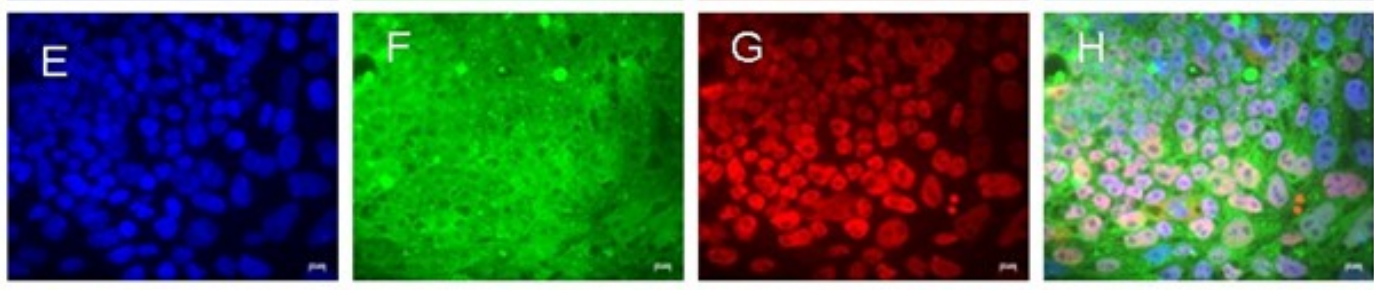

Control
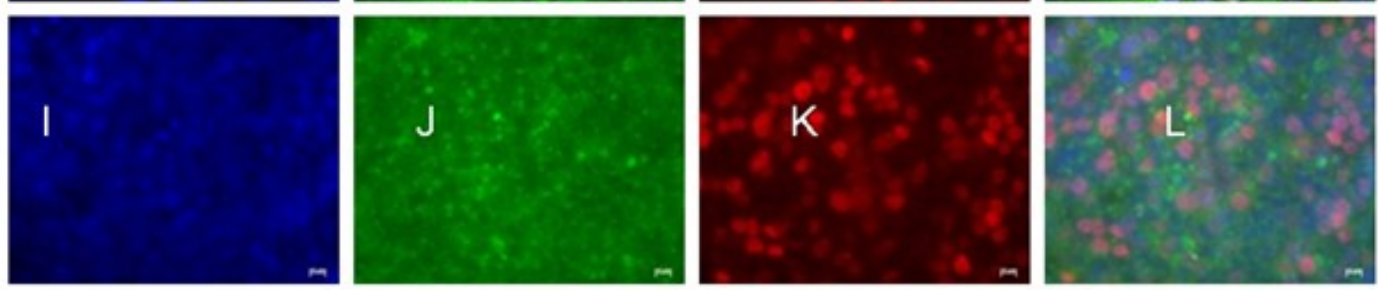

\section{Hormone}

Testicular

extracts

\section{DAPI}

C-KIT

NANOG

\section{MERGE}

Fig. (4). Upper panel: Immunolocalisation of DDX4 (column 2) and OCT4 (column 3) in ovarian-like structures at day 20. DAPI staining (column 1) and merge (column 4). A-D: Control (KO DMEM-FCS); E-H: Hormone treated; I-L: Testicular extracts treated. Bar $=20 \mu \mathrm{m}$. Lower panel: The immunolocalisation of C-KIT (column 2) and NANOG (column 3) in ovarian-like structures, at day 20. DAPI staining (column 1) and merge (column 4). A-D: Control (KO DMEM-FCS); E-H: Hormone treated; I-L: Testicular extracts treated. Bar $=20 \mu \mathrm{m}$. 

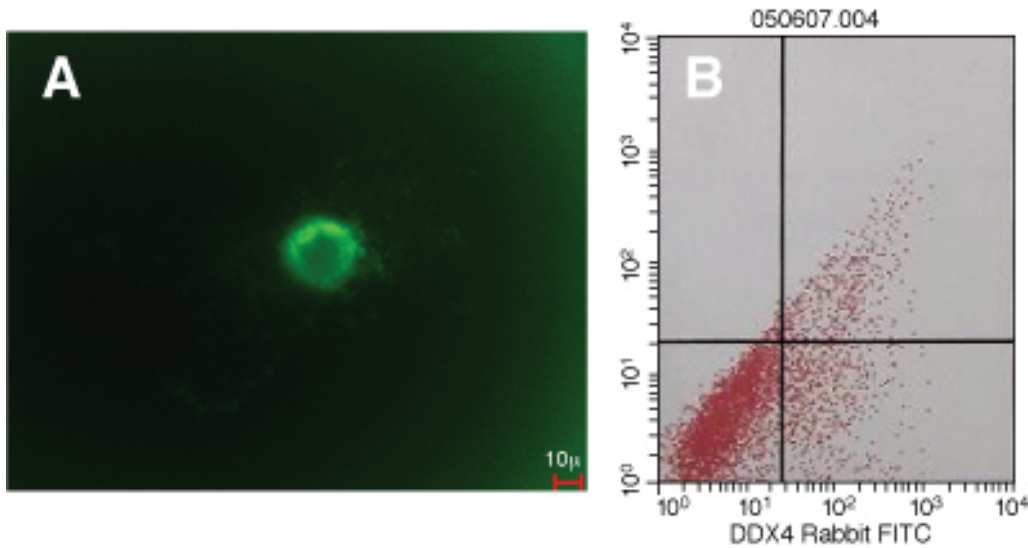

File: 050607.004 - Log Data Units: Linear Values Sample ID: TESTICULAR EXTRACT TREATED Patient: ID

Acquisition Date 05-Jun-07

Gate; G1

Gated Events: 4776

Total Events: 1000

X Parameter: DDX4 RABBIT ATC (Log)

Y Parameter: FL2-H (Log)

Quad Location: 26, 19

\begin{tabular}{l|c|c|c|c|c} 
Quad & Events & \%Gated & \%Total & X Mean & X Geo Mean \\
\hline UL & 56 & 1.17 & 0.56 & 20.82 & 20.65 \\
UR & 404 & 8.46 & 4.04 & 175.90 & 117.82 \\
LL & 3717 & 77.83 & 37.17 & 7.50 & 6.07 \\
LR & 599 & 12.54 & 5.99 & 112.15 & 75.25
\end{tabular}

Fig. (5). Flow cytometric analysis of the expression of DDX4 in the testicular extracts treated cells. A, DDX4 positive cells were observed with a fluorescent microscope. B, $12.54 \%$ DDX4 positive cells were obtained in testicular extracts treated samples at day 20 and the DDX4 positive cells were observed with fluorescent microscope. Scale bar $=10 \mu \mathrm{m}$.
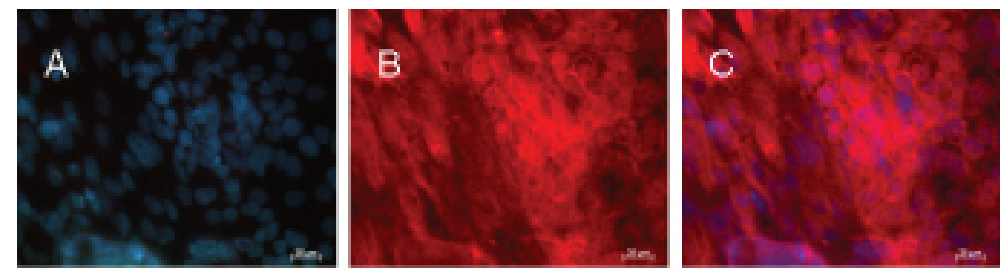

\section{FSHR}
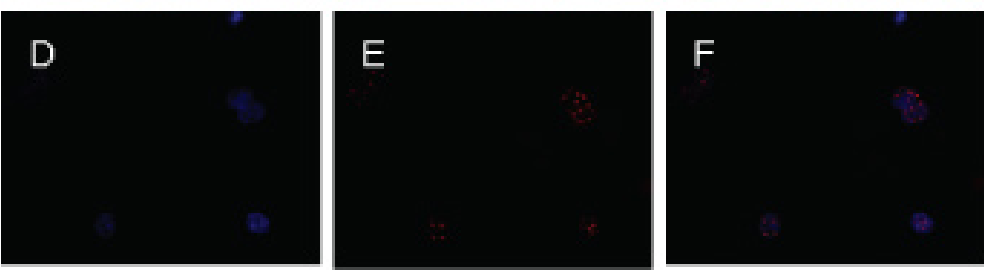

SCP3
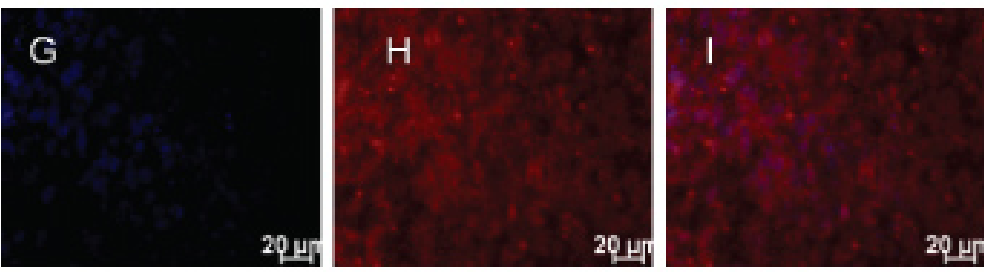

\section{ZP3}
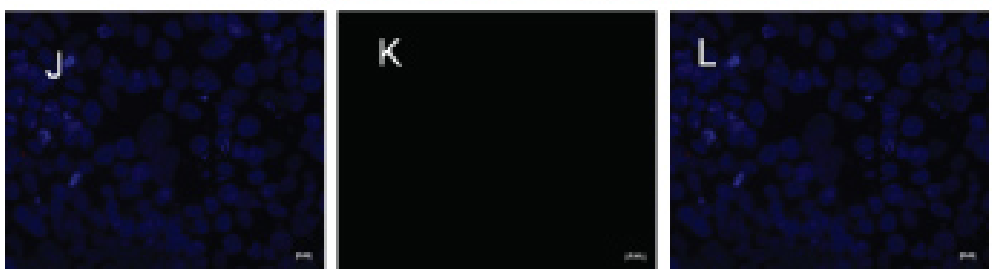

\section{Negative control}

Fig. (6). The immunolocalisation of FSHR, SCP3 and dZP3 in ovarian-like structures, DAPI staining (column 1) and merge (column 4). AC, FSHR; D-F, SCP3; G-I, ZP3; K-L, Negative control. Scale bar $=20 \mu \mathrm{m}$.

(Supplementary Fig. 2). Typical OLCs were positive for specific germ cell markers such as OCT4, C-KIT and DDX4, NANOG, even expressed the essential genes for oocytes development such as FSHR, GDF9, FIGLA, ZP1, ZP2 and ZP3 (Supplementary Fig. 3). The expressions of specific germ cell markers in OLS-putative ovaries i.e. FIGLA, ZP1 and ZP3, GDF9 and FSHR (Fig. 6 and Supplementary Figs. 2 and 3 ) were similar to that observed in ovarian tissues obtained from 19-week human fetal ovary and human fetal ovary germ cells (hOGC). However, the expressions of SCP3 and STRA were weak, even undetectable levels in some samples compared to human fetal ovary. This study also supported that germ cells derived from hESC fail to progress through meiosis [17].

Within the prolonged cultures, more large cell derived OLCs were observed and some developed into blastocystlike structures (Figs. 1 and 2). The markers ZP1 and ZP2 were weakly expressed by putative ovaries and oocytes derived from hESC (Supplementary Figs. 2 and 3). Genes involved with female germ cell specification such as FIGLA, GDF9 and FSHR were up-regulated in putative OLS during EB differentiation in a time-dependent manner (Fig. 7). The expressions of OCT4 and NANOG were variable compared 

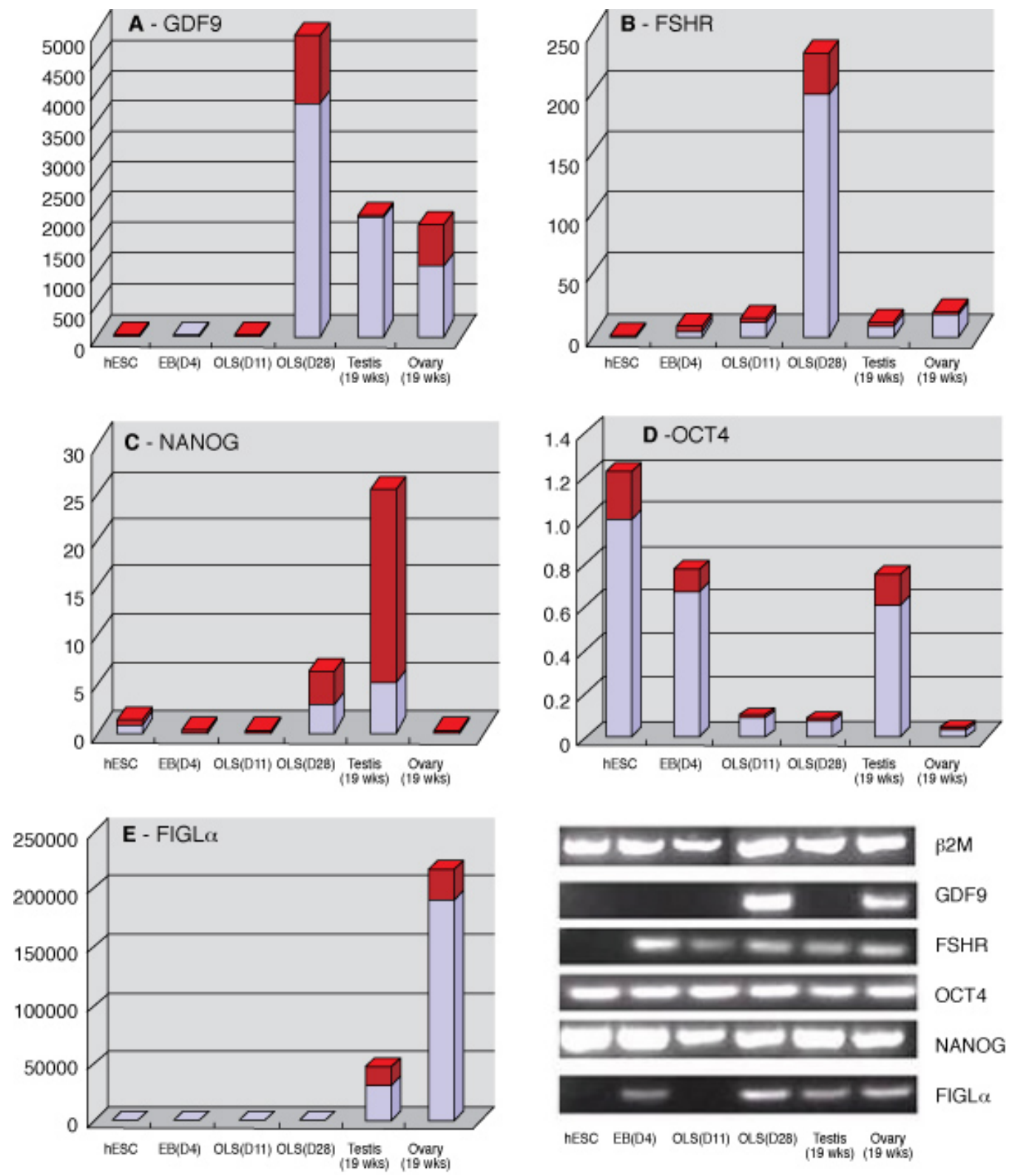

Fig. (7). qPCR for expressions of specific germ cell and oocyte-specific markers in undifferentiated hESC, EB (D4), D11 (OLS), D28 (OLS), Testis (19 weeks), Ovary (19 weeks), Mean normalized expressions are relative to B2M and 18 S. FIGL $\alpha$, GDF9 and FSHR were upregulated in putative OLS during EB differentiation in a time-dependent manner. The expressions of OCT4 and NANOG were variable compared to undifferentiated hESC, human fetal testis and ovary. A, GDF9; B, FSHR; C, NANOG; D, OCT4; E, FIGL $\alpha$.

to undifferentiated hESC, human fetal testis and ovary. These results indicated that ovarian-like structures derived from hESC have the same characteristics as ovarian germ cells. Some expressions of germ cells markers such as OCT4, NANOG and C-KIT were also observed in undifferentiated hESC as revealed by RT-PCR and immunoforescence analyses (Fig. 4 and Supplementary Figs. 2 and 3).

\section{DISCUSSION}

We found that approximately $10 \%$ of the selected EBs derived from hESC can differentiate into germ cell-like or ovarian-like structures after treated with appropriate testicular extracts in combination with FSH and other hormones.
Hübner et al. [3] showed that factors in FBS promote mESCs differentiation into germ cells. FBS alone can mediate the formation of germ cells from mouse ES cells in vitro [3]. But Lacham-kaplan et al. found that FBS was not itself able to induce ESCs into oocytes [5]. In our hands, we found that the differentiation efficiency is different between different batches of FBS (ES qualified and normal FBS). Although the testicular extracts and FBS were not analyzed for cytokine content, it is likely that a small number of human EBs developed into ovarian structures which contained some putative oocyte-like cells when they were cultured in the conditioned medium or testicular extracts or FBS in combination with FSH and hCG. Some putative oocytes were surrounded by one to two layers of flattened cells and have a zona pellucida-like membrane. Moreover, oocyte- 
specific markers such as Fig- $\alpha$, ZP1, ZP2, ZP3, GDF9 and FSHR were expressed by the OLS structures. Quantative RT-PCR results showed that the expressions of oocyte markers such as Fig- $\alpha$, GDF9 and FSHR were up-regulated with the prolonged cultures of OLS-derived hESCs. Undifferentiated hESCs expressed some germ cell markers and EB-derived hESCs may spontaneously activate the meiosis stage [7]. Our results showed that testicular extracts, hormones (FSH and hCG) associated with EGF and unknown growth factors in FBS may reprogram hESCs into germ-like cells and differentiated them into female germ cells, since FSH is essential for the growth and development of germ cells. However, the ovarian-like structures and oocyte-like cells could not develop into mature oocytes in our studies. Novak et al. (2006) also found that the oocytelike cells formed from mESCs fail to progress through meiosis [15].

Hübner et al. first reported the study of in vitro gamete production derived from ESCs. They found follicle-like structures were formed, which included oocyte like cells expressing Oct4, Vasa (Ddx4) and meiotic marker genes (Dmc1, Scp3), and formed blastocyst-like structures after 3 to 4 weeks of culture [3]. A small number of cells within ESC cultures could be reprogrammed to become germ cells by conditioned medium from newborn mouse testis germ cells (TCCs) to support the differentiation of ESCs into ovarian-like structures [5]. Unknown microenvironment conditions within EBs may provide the necessary triggers and signals for the commitment of ESC to the germ line. Growth factors secreted by the germ cells are responsible for the transformation of ESC into gametes [5]. Growth factors such as transforming growth factor (TGF), keratinocyte growth factor (KGF) and hepatocyte growth factor (HGF) can regulate granulosa cells, whereas granulosa cells produce kit ligand $(\mathrm{KL})$ that can influence theca cells and the oocytes. Previous studies have demonstrated that KL, bFGF, LIF, KGF and BMP-4, SCF, IGF-I can influence primordial follicle development [16-20]. BMP-4, SCF, IGF-I and LIF are expressed in the testes that are associated with germ cells or with gonadal somatic cells such as Leydig, Sertoli and testicular somatic cells which mediate interactions between precursor theca cells, granulosa cells and the primordial follicle development. Growth factors and somatic ovarian niche are essential and important for the development of oocytes. These factors are also associated with granulose, ovarian theca cells and with oogenesis [21-27]. Isotani et al. found that the testis environment can support oocyte development [28]. Female PGC were able to continue their oogenesis within a compromised chimeric testis, suggesting that all necessary requirements for oocyte development are also present in the male gonad. Growth factors EGF, TGF $\alpha$ and EGF receptor are important/associated with the development of primordial follicles. Knockout mice have also suggested roles for factors in primordial follicle development. Several genes and transcription factors have been shown to be essential for oocyte survival and primordial follicle development such as ZP1, ZP2, ZP3, GDF9, basic-helix-loop-helix transcription factor Fig $\alpha$ [2627], a winged-helix transcription factor Fox12, and a homeobox NOBOX gene in oocytes [29]. KL, bFGF, LIF, KGF, Müllerian-Inhibiting Substance (MIS), insulin and BMP-4 are specific in their ability to influence primordial follicles. Granulosa cells are the primary cell type in the ovary that provide the physical support and microenvironment required for the developing oocyte. A number of hormones and growth factors, including $\mathrm{FSH}$ and $\mathrm{LH}$, receptors for factors such as epidermal growth factor (EGF), insulin-like growth factor (IGF), and inhibiting substance [anti-Müllerian hormone $(\mathrm{AMH})$ ] have been found to be involved in the granulosa cell differentiation and follicle development. The ovarian theca cell, the inner layer of cells and the theca interna, have a basement membrane separating it from the outermost layer of mural granulosa cells, secret androgens produce progestins under gonadotropin control [29].

GDF-9 is an oocyte-specific member of the TGF $\beta$ family and is expressed by oocytes in the primary stage of follicle development through ovulation. Synergistic actions of GDF9 and BMP-15 have a role in oocyte-cumulus cell interactions in developing follicles, but not in primordial follicles. Synthesis of GDF9 mRNA oocyte from the primary follicle stage until after ovulation is continued [30]. The folliclestimulating hormone receptor (FSH-R) is a seven transmembrane spanning receptor (7TMR) which plays a crucial role in male and female reproduction. The transcription factor FIGa is required for formation of primordial follicles, and activated at E13 in vivo in premeiotic oocytes to regulate the transcription of many genes that promote follicle formation, including $Z P 1$ and $Z P 2$. FIGa is also activated in the germ cell-like cells, together with at least one of its downstream targets, ZP3 [30]. Activation of FIGa in the germ cell-like cells likely recruits gonadal supporting cells, resulting in the formation of the follicle-like structures observed in vitro [30]. Expression of oocyte specific markers such as Fig $\alpha$, ZP1 (a structural protein) and ZP3 in putative ovaries confirms the production of female germ lineage of oocytes, but lack of expression of ZP2 (a secondary receptor for sperm) within the zona pellucida suggests that the oocytes are at an early stage of their growth phase, when mRNAs of the zona proteins ZP1, ZP2, and ZP3 are normally accumulating [6].

Pre-meiotic germ cell markers are expressed in human ES cells, such as OCT4, GDF3, NANOG, STELLAR, DAZL and C-KIT. Human ESCs and germ cells may share aspects of a common molecular program and therefore express similar genes. The expressions of germ cell markers may indicate spontaneous differentiation of part or all of the population of ESCs to germ cells [7]. Overexpression of genes may promote ESC differentiate into germ cells [10], which include VASA, a specific marker of germ cell migration that enters into the gonads and meiosis [17], GDF9, a specific marker of meiotic and post-meiotic germ cell differentiation in oocytes [19-20], and SCP3, a specific marker of meiosis in male and female germ cells [30-34]. Some cells in treated EB-derived human ESCs expressed marker genes specific to different stages of germ line development (e.g., VASA, DAZL). Furthermore, a meiotic marker gene, SCP3 was identified in treated human EBs. We observed some oocyte-like cells derived from hESCs that could develop into blastocyst. OLS derived from hESCs expressed oocytes specific markers such as FIGLA, GDF9, FSHR, ZP1, ZP2 and ZP3. In addition, the expression levels GDF9, FIGLA and FSHR were up-regulated in OLS compared to undifferentiated hESCs, which suggested that some OLS develop into the later stage, but few can develop 
into mature oocytes with the production of ovarian-like structures very rare. These studies suggested the possibility that human ESC may recruit the germ line and undergo meiosis. However, the completion of meiosis derived ESC in vitro might be promoted by additional appropriate germ cell factors and/or somatic cell interactions that are native to the in vivo niche [7]. The culture systems need to be further optimized. Our findings that cell lineage from EB-derived hESCs are mixed and complex, which influence the efficiencies differentiation. Isolation the purity germ cells from EBs based on the specific germ cell markers, and combined growth factors maybe can promote the efficiencies.

Primordial follicle development is hormone independent. The ability of somatic cells in the gonad is an essential requirement for reproduction to control and maintain the process of gametogenesis. The basic functional unit in the ovary is the ovarian follicle that is composed of somatic cells and the developing oocyte. The two primary somatic cell types in the ovarian follicle are the theca cells and granulosa cells. These two somatic cell types are the site of action and synthesis of a number of hormones that promote a complex regulation of follicular development. The elucidation of factors that control ovarian somatic cell growth and development is critical to understand ovarian physiology [32]. Our studies demonstrated that some oocyte-like cells derived ovarian-like structures that are similar to primordial follicles. Some OLS were derived from hESC and the expression of FSHR, GDF9 and FIGLA were upregulated in cultures treated with FSH and hCG in combination with EGF and FBS. During the course of reproductive life, many more primordial oocytes undergo a mysterious demise, while relatively few begin to grow and mature into ovulatory follicles. Follicogenesis and follicle in vitro culture showed that FSH, LH, hCG, estrodiol and some growth factors such as EGF, SCF, BMP and insulin are involved in the oocyte development and maturation [35,36]. Some growth factor signals are present in the testicular cell conditioned media that are related to formation of follicles and oocytes remain to be determined [7]. Our study showed that some ovarianlike structures and putative oocytes were derived from hESC but few can grow into mature follicles. This also suggests that oocyte development in humans is long, extraordinarily complex and not well understood. We found that the formation efficiencies of OLS varied with testicular extracts, FBS and hormones and this was also associated with the quality of EB formation. It is difficult for the oocyte to complete the meiosis development under in vitro environment. Further studies are needed to select the VASA positive cells derived from EBs, and to co-culture these with ovarian somatic cells, which may promote the development of oocytes. ESC, PGC, EGC and inner cell mass (ICM) and the primitive ectoderm (PE) share some similar characteristics. Zwaka et al. [34] review recent evidence that the closest in vivo equivalent of an ES cell is an early germ cell. These reports indicated that the derivation of mammalian germ cells, both female and male, is possible in vitro from pluripotent stem cells. Under appropriate environment, ESC, PGC and EGC may differentiate into male or female germ cells [6]. Testicular extracts and FBS may consist of some growth factors that are helpful for the development of female germ cells in combination with hormones.
Interestingly, Dyce et al. cultured skin stem cells with ovarian follicular fluid and observed cumulus-oocyte-complex appeared, and upon gonadotropin stimulation, oocytelike cells were released from the complex in 10 days. Some of them spontaneously formed blastocyst-like structures, suggesting parthenogeneic activation [35]. These results demonstrated that follicular fluid contains factors that are secreted from granulosa cells, theca cells and oocytes, within the follicles. In our research, OLS were obtained from hESC cultured in testicular extracts and hormones. Many growth factors and hormones such as GDF9, GDF9b, SCF, BMP4, bFGF and oestrogen, which are essential for germ cell specification and development, may be present in follicular fluid or testicular extracts $[35,36]$. Whether these factors alone, or in combination, are responsible for directing the stem cells to enter into the germ cell path, is currently unclear [35].

Recent reports suggest that oocyte production is maintained through continual seeding of the ovary by circulating bone-marrow-derived germ cells in vivo. Bone marrow and peripheral blood may serve as reservoirs of cells responsible for the regenerative capacity [37]. Danner et al. [38] reported that oocyte-like cells (OLCs) are derived from a rat clonal pancreatic stem cell line. Lue et al. [39] injected bone marrow cells from adult green fluorescent protein (GFP) transgenic mice into the seminiferous tubules and the testicular interstitium of busulfan-treated wild-type or c-kit mutant $(\mathrm{W} / \mathrm{Wv})$ mice. The authors found that the transplanted bone marrow cells survived differentiated into sperm like cells. Thus, these studies suggested that the in vitro production of germ cells is possible from ESC and somatic cells.

In conclusion, ovarian-like structures were derived from hESC treated with testicular extracts and in combination with FSH and FBS. RT-PCR, immunological fluorescence staining and flow cytometry analyses showed that these structures are putative ovarian and express oocyte specific markers can develop into blastocyst. These results also showed that production of germ cells derived from hESC is a complex process. This study thus provides an in vitro model to study germ cell formation from hESC as a potential source of oocytes for therapeutic cloning. However, the efficiencies and mechanism remain to be further elucidated.

\section{ACKNOWLEDGEMENTS}

We are thankful to Leonie Gaudry for technical help in FACS of hESC, Daniel Lie for real time PCR and Sylvia Liu for collection of the testes and ovaries. Jinlian Hua is a recipient of the post-doctoral fellowship from The Special Programme for Western Areas from the government of China. Thanks to Professor Bernie Tuch for providing facilities to work on the derivation of germ cells from hESC at the Diabetes Transplant Unit, Prince of Wales Hospital, Sydney, Australia.

\section{ABBREVIATIONS}

mESC $=$ Murine embryonic stem cells

hESC $=$ Human embryonic stem cells 


$\begin{array}{ll}\text { PGC } & =\text { Primordial germ cells } \\ \text { ESC } & =\text { Embryonic stem cells } \\ \text { FSH } & =\text { Oocyte, follicle stimulating hormone } \\ \text { hCG } & =\text { Human chorion gonadotropin } \\ \text { HFTE } & =\text { Human fetal testicular extracts } \\ \text { FBS } & =\text { Fetal bovine serum } \\ \text { ITS } & =\text { Insulin-transferrin-selenium } \\ \text { KO-DMEM } & =\text { Dulbecco knockout } \\ \text { HFF } & =\text { Human fetal fibroblast } \\ \text { bFGF } & =\text { Basic fibroblast growth factor } \\ \text { PBS } & =\text { Phosphate-buffered saline } \\ \text { CFDA } & =\text { Carboxyfluorescein diacetate } \\ \text { PI } & =\text { Propidium iodide } \\ \text { PFA } & =\text { Paraformaldehyde } \\ \text { DAPI } & =4,6 \text {-diamidino-2-phenylindole } \\ \text { TCCs } & =\text { Testis germ cells } \\ \text { TGF } & =\text { Transforming growth factor } \\ \text { KGF } & =\text { Keratinocyte growth factor } \\ \text { HGF } & =\text { Hepatocyte growth factor } \\ \text { PCM } & =\text { Inner cell mass } \\ \text { OLCs } & \text { Orimitive ectoderm } \\ \text { GLP } & \text { Oocyte-like cells } \\ & =\text { Green fluorescent protein } \\ \text { OLS } & =\end{array}$

\section{SUPPLEMRNTRY MATERIAL}

This article is also accompanied with supplementary material and it can be viewed at publisher's web site.

\section{REFERENCES}

[1] Nagano MC. In vitro gamete derivation from pluripotent stem cells: progress and perspective. Biol Reprod 2007; 76: 546-51.

[2] Thomson JA, Itskovitz-Eldore J, Shapiro SS, et al. Embryonic stem cell line from human blastocysts. Science 1998; 282: 1145-7.

[3] Hubner K, Fuhrmann G, Christenson LK, et al. (2003). Derivation of oocytes from mouse embryonic stem cells. Science 2003; 300: 1251-6.

[4] Geijsen N, Horoschak M, Kim K, Gribnau J, Eggan K, Daley GQ. Derivation of embryonic germ cells and male gametes from embryonic stem cells. Nature 2004; 427: 148-54.

[5] Toyooka Y, Tsunekawa N, Akasu R, Noce T. Embryonic stem cells can form germ cells in vitro. Proc Natl Acad Sci USA 2003; 100: 11457-62.

[6] Lacham-kaplan O, Chy H, Trounson A. Testicular cell conditioned medium supports differentiation of embryonic stem cells into ovarian structures containing oocytes. Stem Cells 2006; 24: 266-73.

[7] Clark AT, Bodnar MS, Fox M, et al. Spontaneous differentiation of germ cells from human embryonic stem cells in vitro. Hum Mol Genet 2004; 13: 721-39.

[8] Bucay N,Yebra M, Cirulli V, et al. A novel approach for the derivation of putative primordial germ cells and Sertoli cells from human embryonic stem cells. Stem Cells 2009; 27: 68-77.

[9] Park TS, Galic Z, Conway AE, et al. Derivation of primordial germ cells from human embryonic and induced pluripotent stem cells is significantly improved by coculture with human fetal gonadal cells. Stem Cells 2009; 27: 783-95.

[10] Kee K, Angeles VT, Flores M, Nguyen HN, Pera RAR. Human DAZL, DAZ and BOULE genes modulate primordial germ-cell and haploid gamete formation. Nature 2009; 462: 222-5.

[11] Aflatoonian B, Ruban L, Jones M, Aflatoonian R, Fazeli A, Moore HD. In vitro post-meiotic germ cell development from human embryonic stem cells. Hum Reprod 2009; 24: 3150-9.

[12] Sidhu KS, Tuch B. Derivation of three clones from human embryonic stem cell line by FACS sorting and their characterization. Stem Cells Dev 2006; 15: 61-9.

[13] Häelien AM, Gaustad KG, Collas P. Transient alteration of cell fate using a nuclear and cytoplasmic extract of an insulinoma cell line. Biochem Biophys Res Commun 2004; 316: 834-41.

[14] Klinger FG, De Felici M. In vitro development of growing oocytes from fetal mouse oocytes: Stage-specific regulation by stem cell factor and granulosa cells. Dev Biol 2002; 244: 85-95.

[15] Novak I, Lightfoot DA, Wang H, Eriksson A, Mahdy E, Höög C Mouse embryonic stem cells form follicle-like ovarian structures but do not progress through meiosis. Stem Cells 2006; 24: 1931-6.

[16] Kezele PR, Nilsson EE, Skinner MK. Insulin but not insulin-like growth factor-1 promotes the primordial to primary follicle transition. Mol Cell Endocrinol 2002; 192: 37-43.

[17] Anne-Marie Z, Hans S, Marjan B. VASA is a specific marker for both normal and malignant human germ cells. Lab Invest 2002; 82: 159-66.

[18] Cailleau J, Vermeire S, Verhoeven G. Independent control of the production of insulin-like growth factor I and its binding by cultured testicular cells. Mol Cell Endocrinol 1990; 69: 79-89.

[19] Fitzpatrick SL, Sindoni DM, Shughrue PJ, Lane MV, Merchenthaler IJ, Frail DE. Expression of growth differentiation factor-9 messenger ribonucleic acid in ovarian and nonovarian rodent and human tissues. Endocrinology 1998; 139: 2571-8.

[20] Dong J, Albertini DF, Nishimori K, Kumar TR, Lu N, Matzuk MM. Growth differentiation factor-9 is required during early ovarian folliculogenesis. Nature 1996; 383: 531-5.

[21] Matzuk MM, Burns KH, Viveiros MM, Eppig JJ. Intercellular communication in the mammalian ovary: Oocytes carry the conversation. Science 2002; 296: 2178-80.

[22] Knight PG, Glister C. Local roles of TGF-beta superfamily members in the control of ovarian follicle development. Anim Reprod Sci 2003; 78: 165-83.

[23] Lyrakou S, Hulten MA, Hartshorne GM. Growth factors promote meiosis in mouse fetal ovaries in vitro. Mol Hum Reprod 2002; 8: 906-11.

[24] Demeestere I, Gervy C, Center J, Devreker F, Englert Y, Delbaere A. Effect of insulin-like growth factor-I during preantral follicular culture on steroidogenesis, in vitro oocyte maturation, and embryo development in mice. Biol Reprod 2004; 70: 1664-9.

[25] Wang J, Roy SK. Growth differentiation factor-9 and stem cell factor promote primordial follicle formation in the hamster: Modulation by follicle-stimulating hormone. Biol Reprod 2004; 70: 577-85.

[26] Dean J. Oocyte-specific genes regulate follicle formation, fertility and early mouse development. J Reprod Immunol 2002; 53: 17180 .

[27] Bayne RA, Martins DA, Silva SJ, Anderson RA. Increased expression of the FIGLA transcription factor is associated with primordial follicle formation in the human fetal ovary. Mol Hum Reprod 2004; 10: 373-81.

[28] Isotani A, Nakanishi T, Koboyashi S, Lee J, et al. Genomic imprinting of $\mathrm{XX}$ spermatogonia and $\mathrm{XX}$ oocytes recovered from XX/XY chimeric testes. Proc Natl Acad Sci USA 2005; 102: 403944.

[29] Piketty V, Kara E, Guillou F, Reiter E, Crepieux P. Folliclestimulating hormone (FSH) activates extracellular signal-regulated kinase phosphorylation independently of beta-arrestin- and dynamin-mediated FSH receptor internalization. Reprod Biol Endocrinol 2006; 33: 1-11.

[30] Liang L, Soyal S, Dean J. FIGalpha, a germ cell specific transcription factor involved in the coordinate expression of the zona pellucida genes. Development 1997; 124: 4939-7.

[31] Cauffman G, Van de Velde H, Liebaers I, Van Steirteghem A. DAZL expression in human oocytes, preimplantation embryos and embryonic stem cells. Mol Hum Reprod 2005; 11: 405-11. 
[32] Acevedo N, Smith GD. Oocyte specific signaling and its regulation of mammalian reproductive potential. Front Biosci 2005; 10: 233545.

[33] Hartshorne GM. In vitro culture of ovarian follicles. Rev Reprod 1997; 2: 94-104.

[34] Zwaka TP, Thomson JA. A germ cell origin of embryonic stem cells? Development 2005; 132: 227-33.

[35] Dyce PW, Wen L, Li J. In vitro germline potential of stem cells derived from fetal porcine skin. Nat Cell Biol 2006; 8: 184-90.

[36] West FD, Roche-Rios MI, Abraham S, et al. KIT ligand and bone morphogenetic protein signaling enhances human embryonic stem cell to germ-like cell differentiation. Hum Reprod 2010; 25: 16878.

[37] Johnson J, Bagley J, Skaznik-Wikiel M, et al. Oocyte generation in adult mammalian ovaries by putative germ cells in bone marrow and peripheral blood. Cell 2005; 122: 303-15.

[38] Danner S, Kajahn J, Geismann C, Klink E, Kruse C. Derivation of oocyte-like cells from a clonal pancreatic stem cell line. Mol Hum Reprod 2007; 13: 11-20.

[39] Lue YH, Erkkila K, Liu PY, et al. Fate of bone marrow stem cells transplanted into the testis: potential implication for men with testicular failure. Am J Pathol 2007; 170: 899-908.

(C) Hua and Sidhu; Licensee Bentham Open.

This is an open access article licensed under the terms of the Creative Commons Attribution Non-Commercial License (http://creativecommons.org/licenses/by$\mathrm{nc} / 3.0 /$ ), which permits unrestricted, non-commercial use, distribution and reproduction in any medium, provided the work is properly cited. 